\title{
Hemoglobin calabria leading to undetectable hemoglobin A1C
}

\author{
Itir Sirinoglu Demiriz ${ }^{1}$, Isil Ozbas Tevetoglu' ${ }^{2 *}$, Bülent Uyanık ${ }^{3}$ and Soner Erdin ${ }^{4}$ \\ ${ }^{1}$ University of Health Sciences Dr Sadi Konuk Training and Research Hospital, Hematology, Istanbul, Turkey \\ ${ }^{2}$ University of Health Sciences Dr Sadi Konuk Training and Research Hospital, Internal Medicine, Istanbul, Turkey \\ ${ }^{3}$ University of Health Sciences Dr Sadi Konuk Training and Research Hospital, Medical Genetics, Istanbul, Turkey \\ ${ }^{4}$ University of Health Sciences Dr Sadi Konuk Training and Research Hospital, Biochemistry, Istanbul, Turkey
}

\begin{abstract}
More than 12,000 hemoglobin ( $\mathrm{Hb}$ ) variants have been identified and listed on the HbVar database. Reliable detection of these Hb variants is important for planning hemoglobinopathy screening and genetic counseling. Presumptive diagnosis is usually dependent on dedicated Hb analyzers, e.g. high-performance liquid chromatography (HPLC) or capillary electrophoresis (CE) systems specifically developed for Hb fraction separation and quantification. In most cases, simple Hb variants can be easily identified. Rarely, a novel $\mathrm{Hb}$ molecule formed by the assembly of different defective globin chains could complicate clinical and laboratory diagnostics and requires DNA testing.
\end{abstract}

\section{Introduction}

Glycated hemoglobin (HbA1c) is the gold standard for evaluating long-term glycemic control in patients with diabetes. HbAlc is proposed as an early diagnostic marker and also is used in long term follow up of Diabetes in guidelines published in 2019 by the American Diabetes Association (ADA) [1-4]. Numerous assays were subsequently developed to measure glycated hemoglobins. The principle of all methods is to separate the glycated and nonglycated forms of hemoglobin. This can be accomplished based on differences in charge (usually by HPLC) or structure (usually immunoassays or boronate affinity chromatography) [5]. The Diabetes Control and Complications Trial's reference method for measurement of HbAlc is cation-exchange HPLC(CE-HPLC). Although CE-HPLC is widely used for the measurement of $\mathrm{HbAlc}$, presence of hemoglobin variants may interfere this test, producing falsely high or low values when the variant hemoglobin or its glycated form cannot be separated from either hemoglobin A or HbAlc [6].

Here we report a case of a variant $\mathrm{Hb}$ detected during $\mathrm{HbAlc}$ measurement with CE-HPLC in a diabetic patient. This variant $\mathrm{Hb}$ was Hemoglobin J-Calabria (c.194G>A (p.Gly65Asp)). We would like to discuss the consequences of $\mathrm{Hb}$ variants in interpretation of $\mathrm{HbAlc}$ tests.

\section{Case}

A 56-year-old woman was referred to internal medicine outpatient clinic for diabetes screening. She was a native of Ankara, the capital of Turkey. She reported a normal physical development and no history of anemia, jaundice, abdominal distension or blood transfusions. Her family history was not significant. General physical and systematic examinations were unremarkable. Complete blood count (CBC), fasting plasma glucose and $\mathrm{HbAlc}$ tests ordered. HbAlc was measured by CE-HPLC method in ARKRAY ADAMS A1c HA-8180V. CBC (complete blood count) results were RBC: $4.8 \times 10^{\wedge} 12 / \mathrm{L}, \mathrm{Hb}: 9.8 \mathrm{~g} /$ dL, Hct:28.2\%, MCV: 58.6 f/L. Fasting glucose was $126 \mathrm{mg} / \mathrm{dL}$. An unusual peak was observed in the labile $\mathrm{HbAlc}$ and stabile $\mathrm{HbAlc}$ was $0.0 \%$. Presence of such a high level of labile HbAlc alerted us for a possible presence of hemoglobinopathy. Then the patient was advised to have a hemoglobin variant analysis with HPCL (Thermo Scientific Dİodonex Ultimate 3000). HPLC revealed HbA: 11.3\%, HbA2: 4.7\%, and $\mathrm{HbF}: 4.3 \%$. A peak of $76.8 \%$ unknown hemoglobin. HbAlc level was measured by immunoturbidimetric assay in Dimension RxL Max instrument. HbAlc level was reported as 6.5\%. DNA mutation analysis was performed to detect the unusual hemoglobin variant in the department of genetics, University of Health Sciences Dr Sadi Konuk Training and Research Hospital. DNA isolation was achieved by the salt precipitation method and presence of heterozygote $\mathrm{Hb} \mathrm{J}$-Calabria variant (c.194G>A (p.Gly65Asp) was detected in our patient.

\section{Discussion}

Hb J-Calabria (beta64 (E8) Gly->Asp, also known as J-Bari; J-Cosenza,) is usually detected incidentally. Hematologic parameters are normal in the heterozygote patients. In peripheral smear with cresyl blue, Heinz bodies may be seen. CE-HPLC separates Hb species based on charge differences between HbAlc and other hemoglobins. HPLC shows $\mathrm{Hb} \mathrm{J}$-Calibri and $\mathrm{HbA}$ separatation at alkaline $\mathrm{pH}$; $\mathrm{Hb}$ J-Calibri

${ }^{\star}$ Correspondence to: Isil Ozbas Tevetoglu, University of Health Sciences Dr Sadi Konuk Training and Research Hospital, Internal Medicine, Istanbul, Turkey, E-mail: isil.ozbas@yahoo.com

Key words: hemoglobin, $A 1 C$

Received: June 18, 2019; Accepted: July 05, 2019; Published: July 12, 2019 
moves faster than $\mathrm{Hb} \mathrm{A}$. If the $\mathrm{Hb}$ substitution causes a change in the net charge of the $\mathrm{Hb}$ (as with $\mathrm{Hb}$ variants $\mathrm{S}, \mathrm{C}, \mathrm{D}$, and $\mathrm{E}$ ), then it may cause interference with methods such as CE-HPLC or electrophoresis [7]. HPLC-based ion-exchange methods for $\mathrm{HbAlc}$ have recently been automated, and interferences by $\mathrm{Hb}$ species such as $\mathrm{HbF}$ and $\mathrm{HbS}$ have been minimized. However, several reports have described artificially low or high $\mathrm{HbAlc}$ results with hemoglobin variants such as $\mathrm{Hb}$ Wayne, $\mathrm{Hb}$ Haelen and others when an automated CE-HPLC method is used $[8,9]$. Hb J-Calibri can be isolated by DEAE-Sephadex chromatography. Although we used DNA sequence analysis to detect $\mathrm{Hb}$-Calibri. In $\mathrm{Hb}$ Calibri dna sequence analysis, presumed mutation is on GGC->GAC at codon $64 . \mathrm{Hb} \mathrm{J-Calabria} \mathrm{has} \mathrm{increased} \mathrm{oxygen} \mathrm{affinity;} \mathrm{normal}$ cooperativity and Bohr effect. It is mildly unstable.

As far as we know, HB Calabria has been reported only in members of a French family and in a Chinese male. In one of these cases it is found in combination with beta-thalessemia $[10,11]$. We could not find any cases in the literature about the effect of $\mathrm{Hb}$ J-Calibri on the false measurement of HbAlc. As far as we know, this is the first case reported of Hb J-Calibri variant in Turkey. Hb J-Calibri does not lead to clinical abnormalities, it also does not affect hematologic parameters. However, in our case microcytic anemia was present. By further investigations it was found that this microcytic anemia was due to iron deficiency so oral iron replacement therapy was started. We think that $\mathrm{Hb} \mathrm{J}$-Calibri and other hb variant cases are mostly overlooked. Hb J-Calibri variant should be taken into account for cases that HbA1c levels cannot be evaluated by CE-HPLC method. If the CE-HPLC method is used to measure HbAlc, then careful inspection of chromatograms may identify the presence of aberrant peaks produced by variants. When the HPLC method shows the presence of an uncommon hemoglobin variant, an alternative method to measure HbAlc should be used [12].

\section{References}

1. Giardine B, Borg J, Viennas E (2014) Updates of the HbVar database of human hemoglobin variants and thalassemia mutations. Nucl Acids Res 42: 1063-1069.

2. Fucharoen G, Srivorakun H, Singsanan S (2011) Presumptive diagnosis of common haemoglobinopathies in Southeast Asia using a capillary electrophoresis system. Int $J$ Lab Hematol 33: 424-433.

3. Szuberski J, Oliveira JL, Hoyer JD (2012) A comprehensive analysis of hemoglobin variants by high performance liquid chromatography (HPLC). Int J Lab Hematol 34: 594-604.

4. American Diabetes Association (2014) Standards of medical care in diabetes. Diabet Care 37: S5-S13.

5. Little RR, Sacks DB (2009) HbA1c: how do we measure it and what does it mean? Curr Opin Endocrinol Diabetes Obes 16: 113-118. [Crossref]

6. Bouzid K, Ahmed HB, Kalai E (2014) Prevalence of hemoglobin variants in a diabetic population at high risk of hemoglobinopathies and optimization of HbAlc monitoring by incorporating HPLC in the laboratory workup. Libyan J Med 9: 25768. [Crossref]

7. Little RR, La'ulu SL, Hanson SE, Rohlfing CL, Schmidt RL (2015) Effects of 49 Different Rare Hb Variants on HbA1c Measurement in Eight Methods. J Diabetes Sci Technol 9: 849-856. [Crossref]

8. Rodríguez-Capote K, Estey MP, Barakauskas VE, Burton T, Holmes D, et al. (2015) Identification of $\mathrm{Hb}$ Wayne and its effects on HbA1c measurement by 5 methods. Clin Biochem 48: 1144-1150. [Crossref]

9. Bots M, Stroobants AK, Delzenne B (2015) Two novel haemoglobin variants that affect haemoglobin A1c measurement by ion-exchange chromatography. Clin Chem Lab Med 53: $1465-1471$.

10. Blouquit Y, Thillet J, Beuzard Y, Vernant JP, Dreyfus B (1977) Structural and functional studies of hemoglobin J Cala-bria: beta64 (E8) Gly leads to Asp. Biochim Biophys Acta 492: 426-432. [Crossref]

11. Chen SS, Yang KG, Jia PC, Liang CC, Long GF, et al. (1982) Studies on abnormal hemoglobins in China: structural analysis of a case of Hbj Calabria (author's transl). Zhongguo Yi Xue Ke Xue Yuan Xue Bao 4: 6-8. [Crossref]

12. KurtoÄŸlu AU, Eren E, Erkal A, KurtoÄŸlu E, Yilmaz N (2017) Hemoglobin J-Iran (HBB c.232C $>$ G): Interference with the assay of HbA1c. Clin Chim Acta 465: 80-81. [Crossref]

Copyright: (C2019 Demiriz IS. This is an open-access article distributed under the terms of the Creative Commons Attribution License, which permits unrestricted use, distribution, and reproduction in any medium, provided the original author and source are credited. 